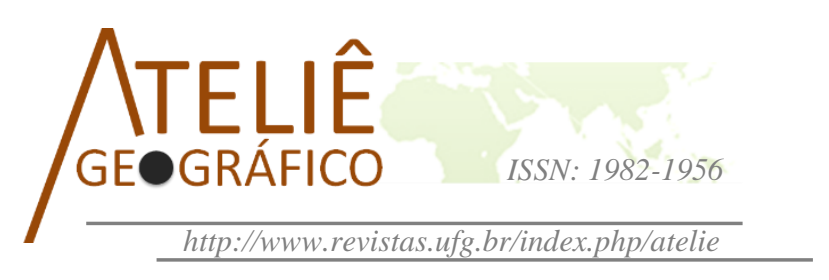

\title{
Queijos diferentes, origem geográfica comum: história e tradição da produção dos queijos do Marajó
}

\author{
Different cheeses, common geographical origin: history and \\ tradition of Marajó cheese production
}

\author{
Quesos diferentes, origen geográfica común: historia y \\ tradición de la producción de los quesos de la isla de \\ Marajó
}

\author{
Elcio Costa do Nascimento \\ Universidade Federal do Rio Grande do Sul \\ elcioncosta@gmail.com
}

Benedito Ely Valente da Cruz
Universidade do Estado do Pará
bvalente7@uepa.br

Miqueias Freitas Calvi

Universidade Federal do Pará

miqueiascalvi3@gmail.com

\begin{abstract}
Resumo
Este trabalho apresenta uma reflexão sobre a história da produção dos queijos (manteiga e creme) do Marajó/PA, Brasil. A pesquisa, de caráter qualitativo, utilizou como ferramentas e metodologias: entrevista semiestruturada e história oral temática. Buscou-se realizar resgate histórico da produção dos queijos; analisar as formas de transmissão do conhecimento e do modo de produção; e iniciar debate sobre as dificuldades enfrentadas para a preservação dessas práticas frente às exigências da regularização sanitária dos órgãos fiscalizadores. Como resultado, observou-se a importância socioeconômica, histórica, social e cultural da produção local de queijo para as famílias envolvidas; a adaptação da produção como forma de resistência e manutenção da artesanalidade da produção; o envelhecimento dos profissionais do queijo marajoara e a diminuição do número de pessoas interessadas em desenvolver a atividade. Esta pesquisa aponta para o grau de fragilidade desse modo de produção e a necessidade de elaboração de políticas públicas que incentivem, preservem e fomentem o conhecimento tradicional e a produção artesanal dos queijos do Marajó.

Palavras-chave: Sucessão familiar; Territorialidade; Produção Familiar; Queijo artesanal.
\end{abstract}




\begin{abstract}
This work presents a reflection on the history of cheese production (butter and cream) in Marajó, PA, Brazil. The qualitative research used the following tools and methodologies: semi-structured interview and themed oral history. We sought to perform a historical rescue of cheese production; to analyze the forms of knowledge transmission and production mode; and to start a debate on the challenges faced in order to preserve those practices given the requirements of sanitary regularization required by the inspection agencies. As a result, we observed the socioeconomic, historical, social and cultural importance of local cheese production for the families involved; the adaptation of production as a form of resistance and maintenance of the artisanal production; the aging of marajoara cheese production professionals and the decrease in the number of people interested in developing the activity. This research points to the degree of fragility of this mode of production and the need to create public policies that encourage, preserve and foster traditional knowledge and local artisanal production of Marajó cheeses.

Keywords: Family succession; Territoriality; Family Production; Artisanal cheese
\end{abstract}

\title{
Resumen
}

Este trabajo presenta una reflexión sobre la historia de la producción de los quesos (mantequilla y crema) del Marajó, PA, Brasil. La investigación cualitativo utilizó como herramientas y metodologías: entrevista semiestructurada e historia oral temática. Se buscó realizar rescate histórico de la producción de los quesos; analizar las formas de transmisión del conocimiento y del modo de producción; e iniciar debate sobre las dificultades enfrentadas para la preservación de esas prácticas frente a las exigencias de la regularización. Como resultado, se observó la importancia socioeconómica, histórica, social y cultural de la producción local para las familias implicadas; la adaptación de la producción como forma de resistencia y de mantenimiento de la artesanía de la producción; el envejecimiento de los profesionales del queso marajoara y la disminución del número de personas interesadas en desarrollar la actividad. Esta investigación apunta el grado de fragilidad de ese modo de producción y la necesidad de elaboración de políticas públicas que incentiven, preserven y fomenten el conocimiento tradicional y la producción artesanal de los quesos del Marajó.

Palabras clave: Sucesión familiar; Territorialidad; Producción Familiar; Queso artesanal.

\section{Introdução}

A escolha do alimento, da comida e o ato de comer são, segundo Canesqui e Garcia (2005), repletos de significados pessoais, sociais, culturais, ambientais e econômicos. Alimentamo-nos para suprir necessidades nutricionais e calóricas e por questões simbólicas, provenientes da sociedade, do meio onde habitamos e das experiências e situações pelas quais passamos (CANESQUI; GARCIA, 2005).

Fonseca et al. (2011) afirmam que o comensal contemporâneo tem agregado diversos significados ao alimento que consome: memória, tradição e significados corporais. Este último relacionado diretamente às escolhas alimentares com sua saúde e qualidade de vida. Esta preocupação pela segurança dos alimentos tem aumentado nos últimos anos, em decorrência da contaminação ocasionada pelo uso indevido de insumos 
agrícolas e desconhecimento das práticas utilizadas na produção dos alimentos (ALLEN, 2010; MEDEIROS e MARQUES, 2013; POULAIN, 2013).

O distanciamento entre o produtor e o consumidor acarreta desconfiança em relação aos produtos adquiridos, em decorrência do desconhecimento de sua origem, do seu conteúdo e das formas de preparo e produção empregadas, gerando uma espécie de "ansiedade contemporânea" ${ }^{1}$ em relação ao alimento. O desconhecimento torna o alimento sem identidade, propiciando a elevação do grau de desconfiança sobre a presença ou ausência de agrotóxicos, de sua "pureza" ou "impureza", de ser "limpo" ou "sujo", afetando no aspecto simbólico das práticas alimentares, pois o alimento, como fator simbólico, "constrói" o indivíduo, assim, desconhecer seu conteúdo reflete na formação do próprio indivíduo, descaracterizando-o (MENASCHE, 2010, p. 202).

Nesse contexto, Menasche (2015) afirma a existência de um processo de (re) valorização do rural, dos produtos locais, por parte dos centros e consumidores urbanos, relacionando os produtos do campo a um "tempo em que não havia riscos", sem contaminantes ou elementos que causem risco à saúde (CRUZ, 2012, p. 59). A comida localmente produzida ganha um status de "natural" e "forte", contrariamente ao alimento industrializado considerado "leve" e "fraco" (WAGNER; MARQUES; MENASCHE, 2007, p. 77).

O queijo do Marajó está inserido em uma rede social sustentada por preferências a determinados produtos e produtores, considerados de "melhor sabor", "melhor consistência", "melhor paladar", características que atraem o interesse dos consumidores e uma valorização étnica, tradicional e nostálgica referente às práticas produtivas e alimentares desenvolvidas localmente (MACHADO; MENASCHE; SALAMONI, 2015). Essa rede se desenvolve e fortalece pela aproximação existente entre os agentes envolvidos, gerando uma confiança estabelecida pelo conhecimento da procedência e do modo de produção do queijo consumido, acarretando em uma valorização do produto pelos consumidores.

A produção do queijo do Marajó possui variações de acordo com o local onde é produzido, demonstrando diferentes modos de saber-fazer o queijo, de acordo com a cultura predominante da região do Marajó no qual é desenvolvido, ocasionando um processo de territorialização específica segundo os diferentes tipos de queijo (CRUZ, 2017).

\footnotetext{
${ }^{1}$ Ansiedade gerada pelo desconhecimento dos componentes presentes no alimento, sua forma e técnicas empregadas na produção, aumentando a desconfiança nos produtos adquiridos e levados para o consumo familiar, porém, a mesma sensação de ansiedade é responsável por aumento da mobilidade, material e simbólica, entre campo e cidade, emergindo um rural valorado positivamente, idealizado (MENASCHE, 2010).
} 
O Território do Marajó é formado por dezesseis (16) municípios que compõem a Mesorregião Geográfica do Marajó (IBGE, 1992). Tem área territorial de $104.140 \mathrm{~km}^{2}$, distribuída em três microrregiões (MRG): Arari, Furos de Breves e Portel. A pesquisa foi realizada na Microrregião do Arari, com enfoque nos municípios de Soure e Cachoeira do Arari (Figura 01). Esses municípios se destacam por serem os maiores e mais tradicionais produtores de queijo dessa Microrregião.

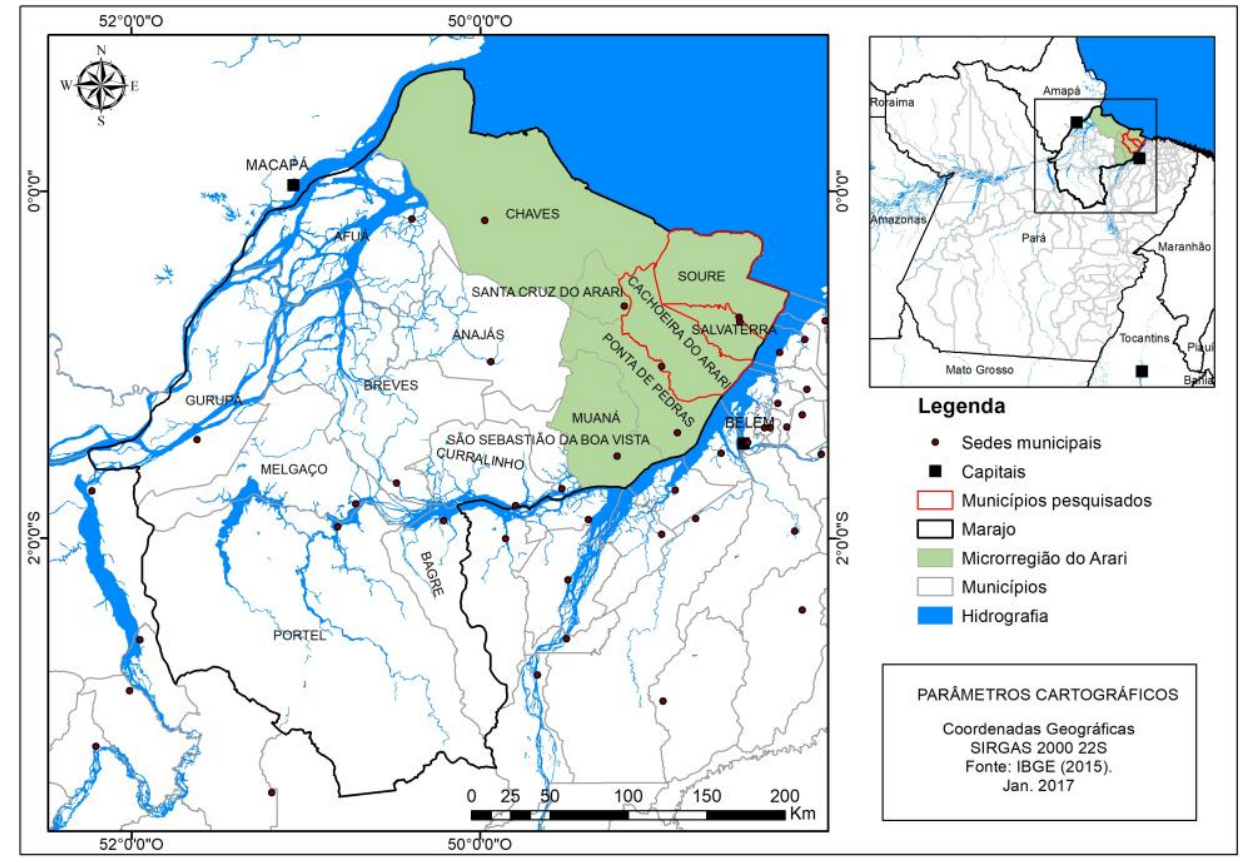

Figura 01: Mapa da Mesorregião do Marajó. Fonte: IBGE (2015).

A coleta de dados foi realizada de março a julho de 2016. Selecionou-se produtores de queijos em atividade, aposentados e ex-empregados de fazendas e queijarias tradicionais da região. As entrevistas foram feitas nas residências e/ou estabelecimentos agropecuários dos entrevistados. Os dados foram coletados por meio de entrevista semiestruturada (POULAIN; PROENÇA, 2003) e história oral temática (MARQUES et al., 2015).

A entrevista semiestruturada - guiada por perguntas-chave, porém não fechadas - objetivou estimular o entrevistado a falar abertamente sobre determinados assuntos, sem perder o foco da pesquisa e o direcionamento da entrevista. Através dessa metodologia buscou-se criar um ambiente confortável, no qual o entrevistado pudesse se expressar livremente, sem as limitações criadas por um questionário. 
A história oral temática visou obter informações sobre os entrevistados relacionadas à história das famílias, sua ligação com a produção do queijo do Marajó e as formas de transmissão do conhecimento do saber-fazer local. Buscou-se compreender as formas de transmissão desse conhecimento, através da reconstrução do passado e entender o presente das famílias, suas dificuldades e formas de resistência ao longo dos anos.

O objetivo da pesquisa consiste em realizar resgate histórico da produção e dos produtores, buscando analisar as formas de transmissão familiar do saber-fazer do queijo marajoara; e iniciar discussão sobre os riscos para a preservação desse saber-fazer frente aos processos de regularização ao qual esse produto está submetido, bem como do processo de sucessão geracional.

\section{Resultados e discussão}

A história da pecuária do Marajó remonta ao século XVII. No século XVIII já era considerada a atividade econômica mais importante da ilha, principalmente na região do Arari, dadas as extensas áreas de campos naturais em terrenos planos, propiciando o desenvolvimento da pecuária e da agricultura. A primeira importação de gado para a capital (Belém) data de meados do século XVII (1644), proveniente de Cabo Verde, sendo, posteriormente, levada para as "campinas marajoaras", experiência que se relevou altamente promissora. A primeira fazenda foi fundada em 1680, por Francisco Rodrigues Pereira, seguido pelos frades mercedários (1696), considerados os "maiores investidores da criação bovina e cavalar na Ilha do Marajó", ambos na região do Arari (BARATA, 1973; MIRANDA NETO, 1976; LIMA, 1996).

O município de Cachoeira do Arari, localizado na área dos campos naturais, em 1872 era o mais importante fornecedor de carne de gado, devido sua localização, próximo ao rio Arari, facilitando o acesso, transporte e navegação dos produtos do município para Belém. Porém, segundo Lima (1996), os produtos cárneos provenientes da ilha não conseguiam suprir as necessidades da capital do Estado, devido à má qualidade (transporte e formas de abates inadequados) e irregularidade na oferta. Várias ações foram tomadas para remediar a situação, inclusive a construção de abatedouros locais, visando melhorar a qualidade da carne. Barata (1973) demonstra, através de estudo de relatórios e documentos oficiais sobre a produção na Ilha do Marajó, a evolução e a decadência da pecuária na região em pouco mais de 200 anos (1680-1885), na qual a Ilha do Marajó saiu de área exportadora de gado para Lisboa, Antilhas e Caiena, para uma "indústria pastoril" incapaz de produzir para o consumo da província.

Neste contexto de crise da pecuária bovina tradicional, a bubalinocultura se destacou como alternativa. As boas condições naturais da ilha, seu ecossistema de campos e a boa capacidade adaptativa do búfalo a diversos ambientes (DAMASCENO, 2010) propiciaram seu rápido desenvolvimento, tornando-se um elemento característico, econômica e culturalmente da região (BARBOSA, 2005). 
Existem muitas narrativas sobre o surgimento do búfalo no Brasil, entre elas há somente um consenso, que sua introdução ocorreu pela Ilha do Marajó no final do século XIX, durante a década de 1890 (BARBOSA, 2005; FIGUEIREDO, 2006), espalhandose pelo restante do país. Atualmente, a região Norte detém $64 \%$ do rebanho bubalino nacional, sendo o estado do Pará o maior produtor, com 36\%. Na Ilha do Marajó, a microrregião do Arari se destaca na produção de carne, leite e queijo de búfalo, com um rebanho efetivo (em 2017) de 320.784 cabeças, destacando-se os municípios de Chaves, Soure e Cachoeira do Arari, com 34, 21\%; $13,83 \%$ e 5,82\% do efetivo, respectivamente (IBGE, 2017).

No entanto, apesar de sua atual importância, a inserção do búfalo no Marajó gerou grande resistência, visto que seus produtos não eram apreciados pela população local. Tal fator contribuiu para existência de rebanhos vivendo sob baixíssimo ou nenhum manejo, assimilando-se quase a um sistema selvagem, desencadeando degradação dos campos naturais, conforme relatado.

[...] quando trouxe esses búfalos pra cá, contado pelos mais antigos, foi visto com maus olhos, por que o búfalo degradava; aquela questão de não tomarem o leite, não gostarem da carne [...] agora, aqui pra nós [nos dias atuais], se o açougue matar uma rês comum [gado bovino], ele passa três dias pra vender. Outro açougue concorrente mata um búfalo, todo mundo corre pro búfalo. Já mudou o pensar, a cultura, é uma carne que enseba menos [menos gordura], mais leve um pouco (E1, queijeiro da Comunidade do Jabuti, Cachoeira do Arari, 2016).

Nesse contexto, o Búfalo ganha cada vez mais importância e espaço na pecuária marajoara. A versatilidade produtiva (para carne, leite e trabalho) e adaptativa dessa espécie contribuíram para essa realidade. Além disso, o Búfalo possui características produtivas superiores, comparadas ao bovino, tornando sua criação e produção mais rentável: menor tempo de abate, com maior produção cárnea; maior rendimento industrial do leite para produção de derivados, devido ao maior teor de proteína, gordura, minerais (cálcio e fósforo) e lactose; menor teor de gordura muscular na carne e menos colesterol, o que a torna mais saudável para consumo (DAMASCENO, 2010). Entre esses e outros fatores, o búfalo ganhou a preferência entre os consumidores e produtores da Ilha do Marajó para a produção de carne, de leite e no fabrico do "famoso" queijo do Marajó.

\section{Queijos diferentes, origem comum}

A história da produção do queijo do Marajó, reconhecido por ser produzido a partir do leite de búfala, remonta a tempos anteriores à chegada dessa espécie na ilha. Autores como Barata (1973), Miranda Neto (1976) e Lisboa (2012) relatam a existência de fazendas na microrregião do Arari que dedicavam parte de suas atividades ao fabrico de queijos e manteigas desde o século XVIII, ou seja, a produção do queijo do Marajó existe há pelo menos 200 anos, sendo feito, originalmente, com leite bovino. Esta 
informação foi confirmada através dos relatos obtidos dos produtores de queijo mais antigos. Fato que instigou os pesquisadores a buscar, através das falas dos entrevistados, o momento ou período em que teve início o uso do leite de búfala na produção de queijos na Ilha de Marajó.

A receita, segundo informação local e histórica, chegou ao Brasil junto com os primeiros colonizadores da ilha (portugueses e franceses), espalhando-se pela microrregião do Arari e tornando-se, atualmente, "parte do hábito alimentar do paraense [...] sendo produzido quase que exclusivamente com leite de búfala" (FIGUEIREDO, 2006, p. 32).

A produção do queijo é de caráter, principalmente, familiar e artesanal, elaborado em pequenas propriedades por meio de um saber-fazer acumulado há mais de dois séculos - o que possibilita uma forte identidade territorial. Agregando características únicas ao produto, adquiridas devido ao sistema de criação dos animais alimentados em pastagens naturais - e pela utilização de leite cru, em sistema de produção manual de baixo nível tecnológico, expressos em dois modos de produção de queijo artesanal.

Quando você pega os queijos daqui da nossa região, você sente que é um queijo diferente, o sistema de criação aqui, a maioria é a natureza que cria pro cara. Você vê pasto plantado aqui tem muito pouco. Você pega um leite daqui de dentro do Gurupatuba e pega um leite aqui da nossa região, dá uma diferença danada, questão de gosto, paladar. (E2, queijeiro da Comunidade do Jabuti, 54 anos, 2016).

Tal como Menezes (2011, p. 1), constatou-se que a produção dos queijos artesanais está "enraizada na história da vida de homens e mulheres que compartilham a mesma identidade cultural". Os dados demonstram essa identificação com o território e a cultura local. A continuação da produção e o repasse do conhecimento é uma forma de reproduzir essa tradição existente e resistente há anos. Essa autoidentificação e o sentimento de reconhecimento e pertencimento a uma comunidade/cultura/território podemos observar na fala abaixo:

[...] o que eu sempre fiz, que não tinha queijo do Prudêncio, nem do Branco, nem do Quebra-pote, tinha queijo da comunidade do Jabuti. Se estamos trabalhando num queijo que é daqui da comunidade do jabuti, vamos fazer da comunidade do jabuti (E2, queijeiro da Comunidade do Jabuti, 54 anos - 2016).

Embora alguns trabalhos destaquem que a produção de queijo de búfala teve início com o fazendeiro João Batista Lima, o Coronel Lima, da Fazenda Gurupatuba, no município de Cachoeira do Arari (FIGUEIREDO, 2006; MIRANDA NETO, 1976), nossos dados de campo e os relatos unânimes dos entrevistados apontam que o primeiro criador a explorar o búfalo para produção de leite e queijos foi o fazendeiro Francisco 
Soares Mello, o Coronel Mello, de origem nordestina, proprietário da então Fazenda Santana, atual Tucumã.

[...] quem apareceu por aqui com essa obra de fazer queijo, era um senhor que morava na Fazenda Tucumã, antiga Santana, senhor Francisco Mello. Foi ele quem apareceu com essa produção de queijo. Meu pai, velho Lósinho, começou a trabalhar com ele, aprendeu com ele (E3, queijeiro, Cachoeira do Arari, 2016).

Segundo os entrevistados, nas localidades do Jabuti e Retiro Grande, o Coronel Mello foi um grande conhecedor da "arte" da queijaria, várias vezes apontado como "profissional do queijo", sabendo reconhecer quando o queijo produzido seria um produto bom ou problemático. Sua especialidade era produção de queijo tipo manteiga, iniciando e ensinando o modo de produção aos produtores locais e dando início à disseminação do produto na localidade e na Ilha de Marajó.

Chico Mello era um cearense ${ }^{2}$. Foi aonde eu aprendi a amansar vaca, a tirar leite, foi lá que eu aprendi, com ele. Agora ele era profissional em queijo, né. Quando ele botava a coalhada pra esquentar, se fosse dá problema, ele mais ou menos sabia logo. Hoje o queijo vai dá problema, [dizia ele]. Cansei de ver ele fazendo isso. (E4, ex-empregado da Fazenda Santana, tirador de leite, Cachoeira do Arari, 2016).

A produção de queijo na Fazenda Santana teve início na década de 1920, chegando a produzir $100 \mathrm{~kg}$ de queijo tipo manteiga por semana. Segundo os relatos, o período da produção de queijo organizado pelo Coronel Mello durou menos de dez anos, quando este mudou-se para Belém por questão de saúde. Porém, seus conhecimentos na produção do queijo foram transmitidos aos empregados, entre eles, o Senhor Vicente Gonçalves Portal, o Seu Lósinho, o primeiro trabalhador da região e o mais importante mestre queijeiro da região, responsável por ensinar as técnicas da produção para seus familiares e trabalhadores locais. Seu Lósinho, originário de Salvaterra, casou com uma mulher da região do Jabuti e passou a trabalhar na Fazenda Gurupatuba, com o Coronel Lima.

P: Ele produzia muito queijo (o Coronel Mello)?

E: Produzia, 10 latas de 10 quilos por semana. Quem levava era o papai pra Belém. Agora a Gurupatuba superava ele; na Gurupatuba era 400 e poucas vacas, né. Era muita gente, era muito queijo (E4, ex-empregado da Fazenda Santana, tirador de leite, Cachoeira do Arari, 2016).

A Fazenda Gurupatuba produziu queijo, tipo manteiga, de 1920 até o fim dos anos 1990. Essa fazenda foi chamada de "a grande escola dos queijeiros" (E2, queijeiro, Comunidade do Jabuti), pois as famílias que trabalhavam na localidade aprenderam lá a

\footnotetext{
${ }^{2}$ Não houve um consenso sobre o Estado de origem do Coronel Mello (Ceará, Pernambuco ou Piauí).
} 
fazer o queijo tipo manteiga. "Os queijeiros todos dessa região [Jabuti e Retiro Grande], os mais velhos, saíram do Gurupatuba e Santana" (E3, queijeiro, Comunidade do Jabuti), demonstrando a importância e influência dessas duas propriedades na disseminação do saber-fazer o queijo no Marajó.

O Gurupatuba era a fazenda que arrumava trabalho pra todo mundo e de lá começaram a aprender a fazer queijo. Eu garanto uma coisa pra vocês, todos os queijeiros, aqui do jabuti, têm um pouco de Gurupatuba no saber de fazer queijo (E2, queijeiro do Jabuti, Cachoeira do Arari, 54 anos).

Segundo Ribeiro e Ribeiro (2008), o Coronel Lima foi um dos grandes incentivadores da produção de búfalos na região, divulgava seus benefícios e facilitava a compra de rezes por pequenos produtores, que iniciaram produções em suas casas para o autoconsumo e comercialização, ratificando a importância social, cultural e econômica dessa atividade nas comunidades e na microrregião do Arari.

Com relação ao queijo tipo creme, sua produção está dispersa na microrregião do Arari, estando presente nos municípios de Ponta de Pedras, Muaná, Salvaterra e Soure. Entretanto, sua história remete aos produtores do queijo tipo manteiga, de Cachoeira do Arari, tendo em vista que os primeiros produtores a utilizar o leite de búfala na produção de queijos são dessa região (Coronel Mello e Coronel Lima). A história de algumas famílias produtoras desse tipo de queijo, além de dados históricos sobre a existência da atividade queijeira, remete a esse município (BARATA, 1973), evidenciando a importância de Cachoeira do Arari na história da produção do queijo do Marajó.

Desse modo, observa-se a importância do território como identidade social, cultural e econômica, expressando um modo de produção que foi se adaptando, tornando-se referência de um saber-fazer único. Essa identificação, segundo Cruz (2017), é a razão da resistência do modo de produção do queijo do Marajó, buscando não apenas resgatar, mas fortalecer e consolidar uma identidade a um território, a Ilha do Marajó. Porém, como mencionado anteriormente, apesar da similaridade histórica, existem dois tipos de queijos produzidos na região (manteiga e creme), que apesar de compartilharem o mesmo espaço geográfico, possuem territórios diferenciados (Figura 02) e, portanto, "não podem ser vistos como iguais. Suas histórias, a posse da terra, as relações de poder e até mesmo a forma como vêem o Queijo do Marajó são diferentes" (CRUZ, 2017). 


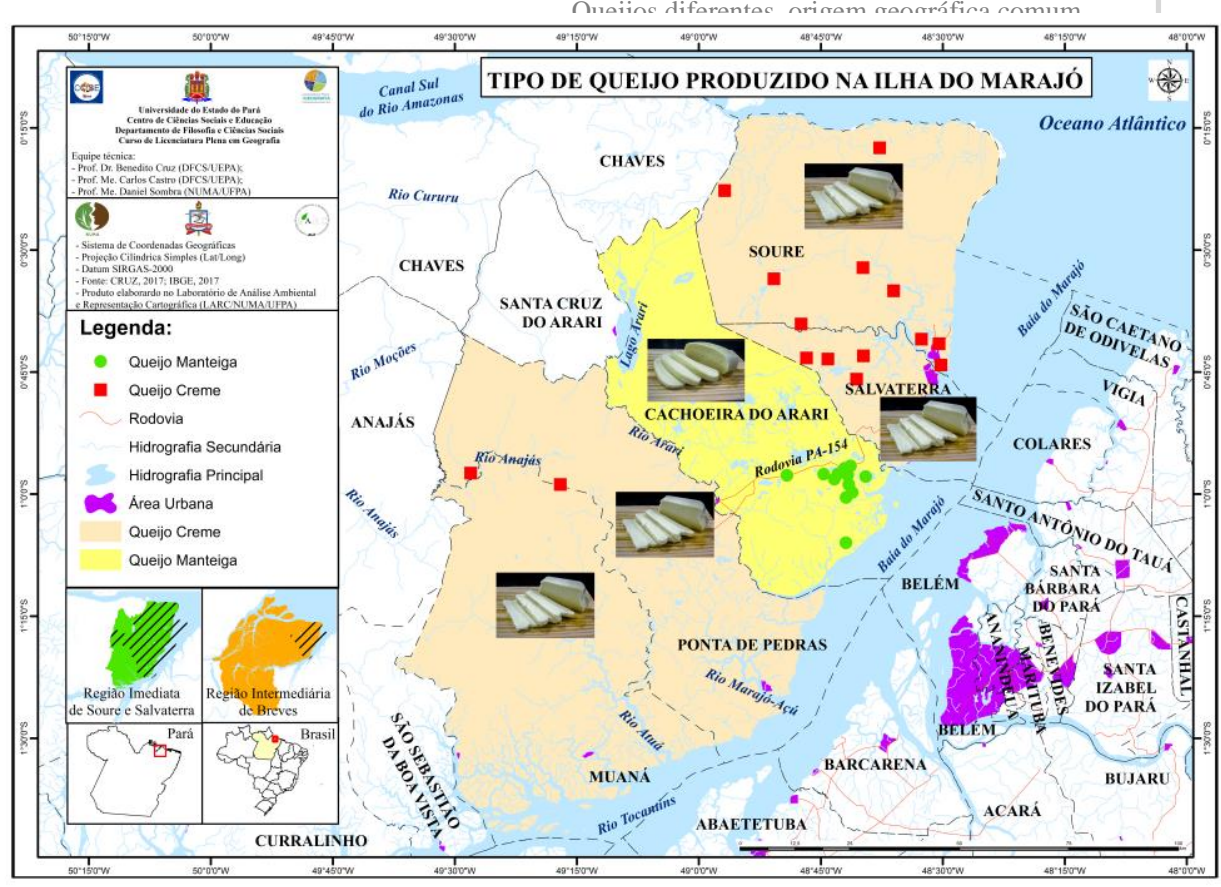

Figura 02: Identificação das queijarias segundo os diferentes tipos de queijos. Fonte: Adaptado de Cruz (2017).

\section{Queijo do Marajó tipo manteiga}

A produção do queijo do Marajó teve seu início na microrregião do Arari, e o queijo tipo Manteiga (Figura 03) foi o primeiro a ser desenvolvido. Atualmente, este queijo é produzido, comercialmente, apenas nos municípios de Chaves e Cachoeira do Arari, sendo as localidades do Jabuti e Retiro Grande os principais pólos produtores. Independentemente do tamanho da propriedade e do perfil do produtor, uma das questões que marca a elaboração desse produto é o sistema de produção artesanal e sua territorialização específica como demonstrado na Figura 02.

A entrada em vigor das normas que regulamentam a produção e comercialização do queijo do Marajó (tipo manteiga e creme) acelerou as mudanças técnicas e de saber-fazer relacionados aos utensílios, os quais aos poucos estão sendo modificados. Anteriormente, utilizavam-se formas de madeiras, depois passaram a usar latas de manteiga e vasilhas plásticas. Atualmente, usam-se embalagens plásticas à vácuo para acondicionamento e comercialização. No entanto, alguns utensílios ainda persistem, como a peneira de jacitara (Desmoncus polyacanthos Mart) e a colher de pau, utilizados por algumas famílias. De acordo com a Agência de Defesa Agropecuária do Estado do Pará (ADEPARÁ), dever-se-ia utilizar peneiras e colheres de plástico por serem mais higiênicas. Mas alguns produtores argumentam que a mudança afeta a qualidade, o sabor e o aspecto final do produto. Por isso continuam utilizando esses utensílios, demonstrando uma resistência embasada no conhecimento tradicional e na tentativa de preservar os modos de produção e as características do produto final. 


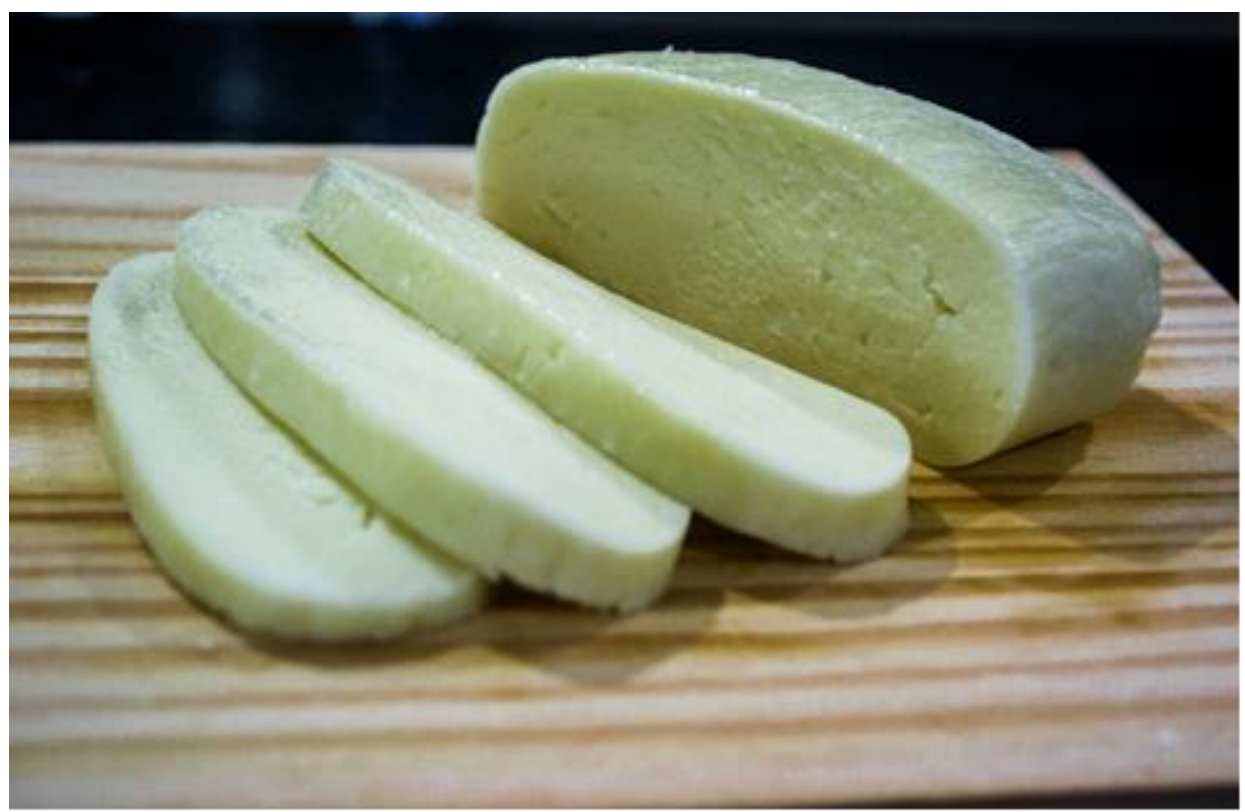

Figura 03: Queijo do Marajó, tipo manteiga.

Fonte: Arquivo pessoal.

Um aspecto interessante da queijaria marajoara é a produção pela prática, , desenvolvida pelo conhecimento adquirido ao longo dos anos. Durante a pesquisa de campo, foi constatado que os produtores de queijo não utilizavam instrumentos para medir as quantidades de cada item necessário. A prática cotidiana permite que os produtores dosem as proporções necessárias para aquela quantidade que será produzida. É esse saber-fazer prático que é repassado de geração para geração no Marajó.

Porque esse nosso modo de trabalho é tudo assim, por prática né. Não tem nada por técnica, o sal a gente coloca sem medo, põe o leite sem medir, a gente conhece por conhecimento, quando tá bom e quando não tá (E3, queijeiro da Comunidade do Jabuti, 75 anos).

Dentre as famílias, com tradição na produção do queijo manteiga na região do Arari, está a família Portal, descendentes do Seu Lósinho. Roberto, também conhecido como Quebra-pote, é um dos atuais "guardiões da tradição", do modo de produção local e um dos mais antigos produtores, ainda em atuação. Nascido e criado nas dependências da Fazenda Gurupatuba, acompanhava o trabalho de seu pai e, através da observação e da prática, absorveu o conhecimento e a expertise que o transformou em uma referência local e regional, quando se trata da produção do Queijo do Marajó.

A Fazenda Gurupatuba, além de local de trabalho, era residência dos empregados e seus filhos. Roberto morou nas dependências dessa fazenda até os 12 
anos, quando se mudou para a comunidade do Jabuti para continuar seus estudos. Seu pai, o Seu Lósinho, já possuía umas cabeças de gado bubalino e cavalar, e Roberto, junto com seus demais irmãos, era o responsável pelo cuidado dos animais. Apesar de acompanhar o trabalho de seu pai na Fazenda Gurupatuba, foi somente quando seu pai deixou de ser empregado da fazenda é que Roberto e seus irmãos "aprenderam mais, porque a frequência foi mais do dia a dia", possibilitando o enraizamento do conhecimento repassado pelo Seu Lósinho. Na época, a produção de leite da propriedade dos Portal era pequena e era necessário comprar leite de outras propriedades do entorno para garantir a produção. Realidade que demonstra a importância da cadeia do queijo na região, beneficiando, direta e indiretamente, as famílias locais, gerando renda aos demais moradores da localidade, possibilitando a reprodução social e econômica, a permanência e preservando o modo de vida da comunidade.

E meu pai saiu de lá [Fazenda Gurupatuba] e veio pra cá [Jabuti] e nós [os filhos] trabalhava com ele, aí que a gente aprendeu mais, porque a frequência foi mais do dia a dia (E3, queijeiro, Cachoeira do Arari, 75 anos).

Aos 23 anos, ao casar-se e constituir família, empregou-se em outra fazenda da região, a Santa Fé, de José Lima (irmão do Coronel Lima), onde trabalhou por 17 anos primeiramente, na produção do leite e do queijo e, posteriormente, no manejo dos animais no campo. Com a falência da Fazenda Santa Fé, Roberto e seus irmãos puderam adquirir lotes da propriedade, iniciando o próprio negócio, ligado ao campo e à produção do queijo marajoara.

Dentre os produtores da "nova geração" está Seu Prudêncio Paixão, produtor da localidade do Jabuti, que embora sempre estivesse relacionado à cadeia de produção do queijo, o produz há apenas 16 anos e sua história também está atrelada à Fazenda Gurupatuba. Seu Prudêncio cresceu envolvido com pessoas que tinham ligação com a produção de queijos, sua referência e influência mais fortes foi seu padrinho, que era trabalhador da Gurupatuba:

Tinha dois tios que faziam, eu aprendi assim, acompanhando em queijarias. Tinha um padrinho, ele fazia queijo no Gurupatuba. Quando eu ia pra lá ele mandava eu prestar atenção, e o que ele me falava eu lembro até hoje (E5, queijeiro do Jabuti, Cachoeira do Arari, 2016).

Seu Prudêncio desenvolveu várias atividades dentro do sistema produtivo do queijo: tirando e carregando leite e queijo, lavando vasilhas, ajudando na produção. Foi acompanhando e trabalhando em diversas funções que Seu Prudêncio aprendeu o ofício de queijeiro e hoje é uma referência na região do Jabuti, possuindo a única queijaria particular com registro de produto artesanal concedido pela ADEPARÁ no município de Cachoeira do Arari.

Atualmente, entre as dificuldades enfrentadas pelos produtores está o aumento da fiscalização e as exigências para a construção de queijarias "mais adequadas". Seu 
Prudêncio investiu cerca de 70 mil reais para adequar sua queijaria, embora esteja dentro dos padrões legais, relata que o custo se eleva por diversas outras razões, como as exigências de laudos que comprovem a potabilidade da água utilizada; a qualidade microbiológica e físico-química do leite cru utilizado; análise físico-química e microbiológica do queijo produzido (PARÁ, 2013), entre outros.

Seu Roberto é um dos queijeiros que ainda não conseguiram adequar sua queijaria à legislação, devido ao alto custo do investimento. Embora enfrentando dificuldades, Seu Roberto e os demais queijeiros entrevistados persistem na produção de queijo. O reconhecimento da qualidade dos seus produtos pelos consumidores, locais e de outras regiões, garantem clientela fiel que demonstra predileção por determinados produtos e produtores, desenvolvida através de laços de confiança, perpassando questões vinculadas à legislação e certificações municipais, estaduais e/ou federais de sanidade e garantem um nicho de mercado baseado, segundo Cruz (2012) e Cruz e Menasche (2014), na "certificação" pela confiança desenvolvida pela maior proximidade, conhecimento da procedência do produto e do modo de produção.

\section{Queijo do Marajó tipo creme}

A história da produção do Queijo do Marajó tem sua origem com a produção do queijo tipo manteiga, pois, no início todas as famílias envolvidas nessa atividade produziam apenas esse tipo de queijo. A partir do final da década de 1920, início de 1930, quando da inserção da desnatadeira no processo produtivo, iniciou-se a diferenciação dos queijos. Surgia o queijo tipo creme (Figura 4). Enquanto esse é mais cremoso, o tipo manteiga é mais rústico, além de possuírem diferenças quanto ao nível de gordura, 35\% e 42\% (SILVA; OLIVEIRA, 2003), textura, produtividade e durabilidade (tempo de prateleira).

O marco principal foi a década de 30 [...] um grupo de fazendeiro de Soure introduziu a desnatadeira e passamos a fazer o queijo tipo creme, com rendimento melhor, com qualidade melhor, e lá (no Arari) eles não acreditaram na desnatadeira e continuaram fazendo o queijo manteiga (E6, Queijeiro, Soure, 2016).

O conhecimento prático, sem medições, protocolos ou receitas, também é característico dos produtores do queijo tipo creme entrevistados, sabendo reconhecer a qualidade do leite e a qualidade do produto, mesmo antes do processo finalizado. A importância desse conhecimento empírico foi observada em situações narradas pelos entrevistados, onde "profissionais da cidade" foram contratados para ministrar cursos de produção de queijo na região, porém não conseguiram "acertar o ponto da massa", recorrendo à ajuda de produtos locais para finalizarem o produto. 
Dentre as famílias de referência na produção do queijo tipo creme no município de Soure, podemos citar duas em especial: os Peua e os Gouvea. Os Peua administram o Laticínio Peua, e os Gouvea o Laticínio Mironga. Embora não possuam produção de leite elevada, os irmãos Peua conseguem manter uma produção significativa, adquirindo leite de outros produtores da localidade e de outros municípios, tornando-se um dos principais compradores de leite da região.

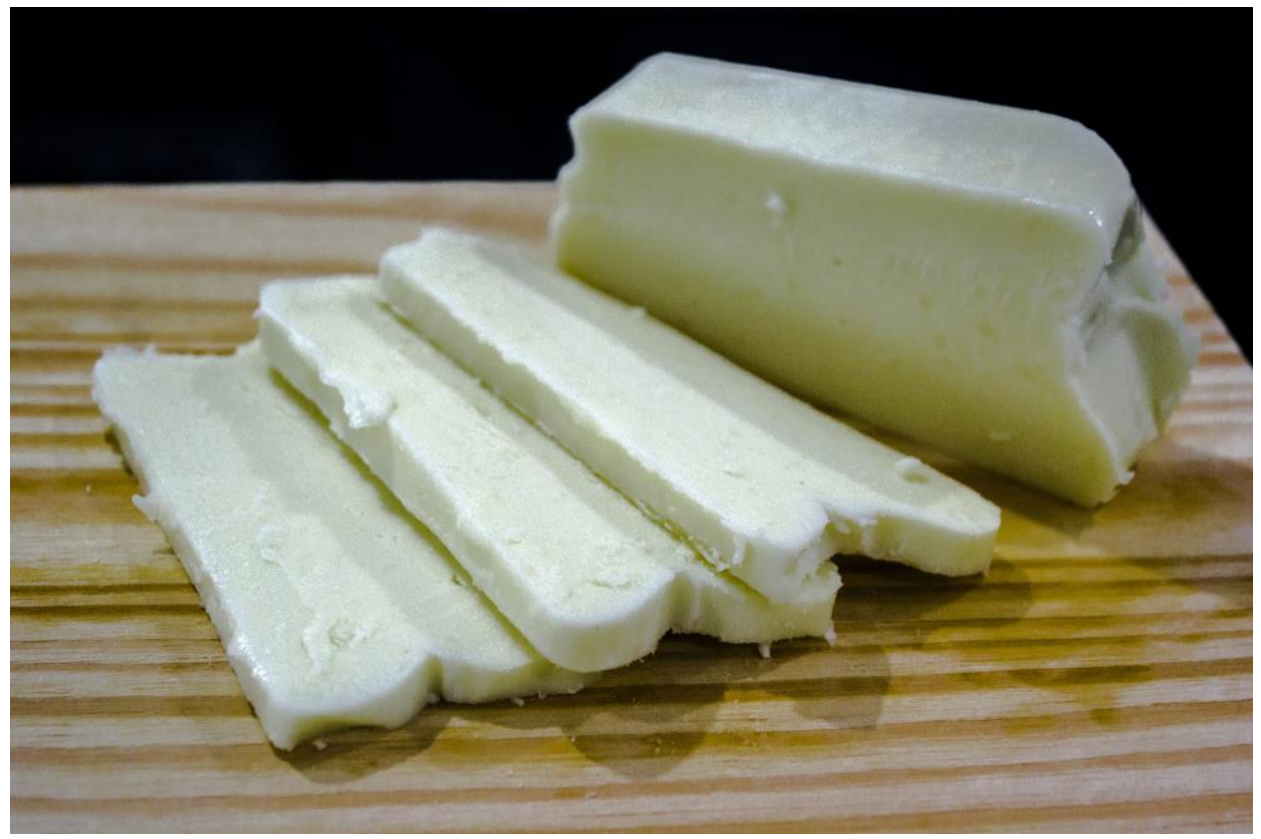

Figura 04: Queijo do Marajó, tipo creme.

Fonte: Arquivo pessoal.

Os irmãos Peua são a $4^{\mathrm{a}}$ geração de produtores da família e a $2^{\mathrm{a}}$ na produção do queijo tipo creme. A mãe dos irmãos Peua, Dona Maria Peua, aprendeu o ofício com a sogra, que por sua vez aprendeu com sua mãe, moradora de Cachoeira do Arari, o que demonstra a importância desse município como o berço da produção de queijo. Foi na gestão de Dona Maria Peua que a produção do queijo mudou do tipo manteiga para o tipo creme. Essa mudança ocorreu devido ao maior rendimento deste ultimo. Segundo Dona Maria Peua, o queijo tipo manteiga "é um queijo bom, gostoso, durativo, mas não rende". Enquanto que o queijo tipo manteiga necessita de 08 a 10 litros de leite para produzir $1 \mathrm{~kg}$ de queijo, o tipo creme requer de 6 a 7 litros para a mesma quantidade.

Da mesma forma que aprendeu na prática, observando a sogra na produção, Dona Maria Peua ensinou os filhos, envolvendo-os no sistema de produção, assim, aprenderam a tirar o leite, cuidar dos animais e produzir o item mais famoso, o queijo marajoara. Esses relatos reforçam as principais características da produção queijeira da 
região, com produção estritamente familiar e da informalidade na transferência do conhecimento entre as gerações, preservando o conhecimento e modo de produção tradicional existente e resistente ao tempo.

A família Gouvêa, de Seu Antônio, tem longa relação com a produção do Queijo do Marajó, desde antes do uso do leite bubalino. Seu filho, Geraldo, relatou que seu Bisavô no final do século XIX já produzia queijo, utilizando o leite bovino, posteriormente, substituído pelo bubalino, influenciados pelo saber-fazer oriundo das fazendas Santana (Coronel Mello) e Gurupatuba (Coronel Lima), em Cachoeira do Arari. Tanto Seu Antônio quanto Seu Geraldo afirmaram que os Coronéis "foram pioneiros não na forma de fazer o queijo (uma vez que a produção já existia muito antes da chegada deles na região), mas no uso do leite de búfala para fazer aquele mesmo queijo que se fazia aqui".

A família Gouvêa sempre esteve ligada à produção agropecuária da região, seja produzindo ou comercializando leite ou queijo. Seu Antônio afirmou ter comercializado leite in natura no município de Soure, no estilo porta-em-porta, um hábito em extinção na região, modificado pelo acesso de novos produtos pelos consumidores, como o leite em pó, mas, também, pelo aumento da fiscalização por parte dos órgãos públicos. Ainda assim, a produção de queijo passou a ser o principal produto dos empreendimentos Gouvêa. Geraldo é a $4^{a}$ geração da família a atuar na produção e, na época da pesquisa, era o responsável pelo gerenciamento do laticínio da família, a Mironga, o primeiro estabelecimento a receber o registro de produto artesanal pela ADEPARÁ em março de 2013.

Nesse contexto, os mais importantes "guardiões" do modo de produção do Queijo do Marajó tipo manteiga estão na região do Jabuti, em Cachoeira do Arari; e do tipo creme em Soure - produtores com larga experiência na "arte" de produzir queijo. Entretanto, os "guardiões" do queijo estão envelhecendo e a juventude da região tem demonstrado pouco interesse nas atividades relacionadas ao campo e na produção dos queijos. As novas oportunidades de formação profissional que surgiram na região nos últimos tempos, associadas à penosidade do trabalho e à falta de incentivos e políticas públicas por parte do Estado estão entre as causas do desinteresse por parte dos "mais jovens". Embora, recentemente, órgãos estadual e federal ${ }^{3}$ de fiscalização tenham homologado normas institucionais que visam o reconhecimento e a regulamentação da produção do queijo do Marajó, os altos custos para adequação das queijarias às normas, a falta de incentivo financeiro e de assistência técnica continuam afastando as novas gerações, atraídas por novas oportunidades de formação e emprego, considerados mais rentáveis e menos penosos, além de desestimular quem já produz. Um dos irmãos Peua, gerente do Laticínio Peua, afirmou que pretende reduzir a produção de queijo que realiza

\footnotetext{
${ }^{3}$ A ADEPARÁ homologou a Lei dos Produtos Artesanais (Lei no 7. 565 de 2011) e a Portaria ${ }^{\circ} 418$ de 2013 (aprova o regulamento técnico de produção do queijo do Marajó e dá outras providências) e o Ministério da Agricultura, Pecuária e Abastecimento (MAPA) homologou a IN nº57 de 2011 (que permite a comercialização de queijos artesanais com maturação menor que 60 dias).
} 
e diversificar suas atividades, fazendo novos investimentos que garantam "uma aposentadoria tranquila".

\section{Considerações finais}

A produção do Queijo do Marajó (tipo creme e manteiga) tem importância significativa na microrregião do Arari, em nível econômico, histórico, cultural e social. A história de sua produção confunde-se com as histórias das famílias e com o aumento da importância da bubalinocultura na região e na preferência da população, que demonstra uma maior predileção em consumir os produtos provenientes desta espécie (carne, leite e queijo). Com elevado apelo territorial, a produção do queijo movimenta a economia local, gera renda, desenvolvimento e trabalho, possibilita a permanência das famílias na região, seu sustento e a reprodução social, econômica e cultural.

Porém, o profissional queijeiro marajoara está envelhecendo e o número de pessoas que desenvolvem a atividade na região está diminuindo, uma vez que as dificuldades impostas pela legislação oneram a continuidade da atividade, além de não haver políticas governamentais adequadas, qualificação e/ou campanhas de conscientização junto à juventude rural das vantagens da produção de queijo. A dificuldade no processo de produção de queijo e a facilidade de acesso à educação pelos mais jovens têm diminuído o interesse destes em continuar com a atividade, sendo necessário, para modificar essa realidade, a criação de incentivos públicos e/ou privados que estimulem o interesse e promovam a continuidade da atividade. $\mathrm{O}$ prolongamento da realidade atual poderá trazer riscos de descontinuidade e perda da produção artesanal do Queijo do Marajó, podendo ser substituída pela produção industrial, de larga escala, já existente na região.

Esta realidade coloca-nos frente ao impasse entre a valorização do saber que emana de práticas territorializadas historicamente e os que emergem de um arranjo sociotécnico que se fundamenta nos princípios da "assepsia". Neste novo contexto, a certificação por confiança perde relevância e o registro de produto artesanal passa a ser a principal ferramenta de normatização e regulação desse saber-fazer.

No entanto, há que se ressaltar que esses dois tipos de saber-fazer são extremamente relevantes, pois conferem singularidade e diferenciação de um mesmo produto, sendo um trunfo no projeto de reconhecimento da Indicação Geográfica que se almeja para esses queijos. Nesse sentido, os produtores de queijo têm um grande desafio, que é manter a tradição e se modernizar, sem perder a qualidade e as características que tornam esse queijo tão peculiar.

\section{Referências}

ALLEN, P. Realizing justice in local food systems. Cambridge Journal of Regions, Economy and Society. 3, 2010.

BARATA, M. Formação histórica do Pará: obras reunidas. Belém: UFPA, 1973 (Coleção amazônica, Série José Veríssimo). 
BARBOSA, T. M. F. Dinâmica dos sistemas de produção familiares da ilha de Marajó: o caso do município de Cachoeira do Arari. 2005. Dissertação (Mestrado em Ciência Animal) Universidade Federal do Pará, Belém, 2005.

CANESQUI, A. M.; GARCIA, R. W. Uma introdução à reflexão sobre a abordagem sociocultural da alimentação. In: CANESQUI, A. M.; GARCIA R. W. (Org.) Antropologia e nutrição: um diálogo possível. Rio de Janeiro: Editora FIOCRUZ, 2005.

CRUZ, B. E. V. O Alvorecer das indicações geográficas na Amazônia: a “corrida” pela IG do queijo artesanal no Marajó, PA. Tese (Doutorado em Geografia) - Universidade Estadual Paulista, 2017.

CRUZ, F. T. Produtos, consumidores e valorização de produtos tradicionais: um estudo sobre a qualidade dos alimentos a partir do caso do queijo serrano dos Campos de Cima da Serra - RS. Tese (Doutorado em Desenvolvimento Rural) - Universidade Federal do Rio Grande do Sul, Porto Alegre, 2012.

CRUZ, F. T.; MENASCHE, R. Tradition and diversity jeopardised by food safety regulations? The Serrano cheese case, Campos de Cima da Serra region, Brazil. Food Policy, 45, 2014.

DAMASCENO, F. A. et al. Adaptação de bubalinos ao ambiente tropical. Revista Eletrônica Nutritime, v. 7, n, 5, 2010.

FIGUEIREDO, E. L. Elaboração e caracterização do “queijo Marajó”, tipo creme, de leite de búfala, visando sua padronização. Dissertação (Mestrado em Ciência Animal) Universidade Federal do Pará, Belém, 2006.

FONSECA, A. B.; SOUZA, T. S. N.; FROZI, D. S.; PEREIRA, R. A. Modernidade alimentar e consumo de alimentos: contribuições socioantropológicas para a pesquisa em nutrição. Ciência \& Saúde coletiva, 16, 9, 2011.

INSTITUTO BRASILEIRO DE GEOGRAFIA E ESTATÍSTICA, IBGE. Censo Demográfico 1991: Resultados preliminares. Rio de Janeiro: IBGE, 1992.

INSTITUTO BRASILEIRO DE GEOGRAFIA E ESTATÍSTICA, IBGE. Sistema (SIDRA), 2015 .

INSTITUTO BRASILEIRO DE GEOGRAFIA E ESTATÍSTICA, IBGE. Censo Agropecuário, 2017.

LIMA, E. F. N. Extrativismo e produção de alimentos: Belém e o "núcleo subsidiário" de Marajó, 1850/1920. Estudos Sociedade e Agricultura, n. 7, 1996.

LISBOA, P. L. B. A terra dos Aruã: uma história ecológica do arquipélago do Marajó. Belém: Museu Paraense Emilio Goeldi, 2012.

MACHADO, C. J. B.; MENASCHE, R.; SALAMONI, G. Comida, identidade e simbolismo: saberes e práticas alimentares na conformação da italianidade na colônia de 
Pelotas. In: MENASCHE, R. (Org.) Saberes e sabores da colônia: alimentação e cultura como abordagem para o estudo do rural. Porto Alegre: Editora da UFRGS, 2015.

MARQUES, F. C.; KRONE, E. E.; CRUZ, P. P.; SCHNEIDER, M. Produzir e comer ecológico: saberes e viveres em transformação. In: MENASCHE, R. (Org.) Saberes e sabores da colônia: alimentação e cultura como abordagem para o estudo do rural. Porto Alegre: Editora da UFRGS, 2015.

MEDEIROS, M., MARQUES, C. F. Plantando ideias inovadoras, colhendo transformações na agricultura familiar: a produção de base ecológica e a construção social de mercados no Sul do Rio Grande do Sul. In: CONTERATO, M. A. et al. (Orgs.) Mercados e agricultura familiar: interfaces, conexões e conflitos. Porto Alegre: Via Sapiens, 2013.

MENASCHE, R. Campo e Cidade, comida e imaginário: percepções do rural à mesa. RURIS, v. 03, n. 02, 2010.

MENASCHE, R. Introdução: alimentação e cultura como abordagem para o estudo do rural. In: MENASCHE, R. (Org.) Saberes e sabores da colônia: alimentação e cultura como abordagem para o estudo do rural. Porto Alegre: Editora da UFRGS, 2015.

MENEZES, S. S. M. Queijo artesanal: identidade, prática cultural e estratégia de reprodução social em países da América Latina. Revista Geográfica de América Central. Número Especial EGAL, 2011.

MIRANDA NETO, M. J. de. Marajó: desafio da Amazônia, aspectos da reação a modelos exógenos de desenvolvimento. Rio de janeiro: Record, 1976.

PARÁ. Portaria n. 0418/2013 ADEPARA: Aprova o regulamento técnico de produção do queijo do Marajó e dá outras providências.

POULAIN, J.; PROENÇA, R. P. C. Reflexões metodológicas para o estudo das práticas alimentares. Revista de Nutrição, Campinas, 16(4), 2003.

RIBEIRO, E. de C.; RIBEIRO, E. de C. Contar de Marajó. Belém: Edição do autor, 2008.

SILVA, V.R., OLIVEIRA, V.L. O Queijo do Marajó tipo "creme" derivado do leite de búfala: uma alternativa para o desenvolvimento sustentável do agronegócio no Município de Soure. Monografia (Especialização em Empreendedorismo Rural e Desenvolvimento Sustentável) - Universidade do Estado do Pará, Belém, 2003.

WAGNER, S. A., MARQUES, F. C., MENASCHE, R. Agricultura familiar à mesa. In: MENASCHE, R. (Org.) A agricultura familiar à mesa: saberes e práticas da alimentação no Vale do Taquari. Porto Alegre: Editora da UFRGS, 2007.

WOORTMANN, E. F. A comida como linguagem. Habitus. v. 11, n. 1, 2013. 


\section{Elcio Costa do Nascimento}

Doutorando em Desenvolvimento Rural na Universidade Federal do Rio Grande do Sul, Mestre em Agricultura Familiar e Desenvolvimento Sustentável pela Universidade Federal do Pará e Graduado em Zootecnia pela Universidade Federal Rural da Amazônia.

Rua São Domingos, Passagem Canaã, 628, Cep: 66077-005, Belém-PA.

E-mail: elcioncosta@gmail.com

\section{Benedito Ely Valente da Cruz Correio}

Doutor em Geografia pela Universidade Estadual Paulista Júlio de Mesquita Filho - UNESP, Mestre em Geografia pela Universidade Federal do Pará e Graduado em Geografia pela UFPA. Atualmente é Coordenador de Apoio à Pesquisa, Extensão e Pós-Graduação no Centro de Ciências Sociais e Educação - CCSE/UEP.

Departamento de Filosofia e Ciências Humanas, Universidade do Estado do Pará, CEP 66.050-540, Belém-Pará, Brasil.

Bvalente7@yahoo.com.br

\section{Miqueias Freitas Calvi}

Doutorando em Ambiente e Sociedade, pela Universidade Estadual de Campinas, Mestrado em Agriculturas Familiares e Desenvolvimento Sustentável, pelo Núcleo de Ciências Agrárias e Desenvolvimento Rural, da UFPA e Graduado em Ciências Agrárias, pela Universidade Federal do Pará. É Professor Adjunto da UFPA, Campus Altamira.

Faculdade de Engenharia Florestal/Departamento de Floresta, Universidade Federal do Pará, CEP 68372-040, Altamira-Pará, Brasil.

E-mail: miqueiascalvi3@gmail.com 